\title{
Alkanibacter difficilis gen. nov., sp. nov. and Singularimonas variicoloris gen. nov., sp. nov., hexane-degrading bacteria isolated from a hexane-treated biofilter
}

\author{
Michèle M. Friedricht and André Lipski \\ Abteilung Mikrobiologie, Universität Osnabrück, 49069 Osnabrück, Germany
}

Correspondence

André Lipski

lipski@biologie.uni-osnabrueck.de
Two Gram-negative, rod-shaped, non-spore-forming bacterial strains were isolated from a hexane-treated, full-scale biofilter from an oil mill. The strains were cultivated with hexane as the sole carbon source. One strain, MN154.3 ${ }^{\top}$, showed a fatty acid profile that contained $16: 0$, 18: 1 cis11 and 19:0 cyclo11-12 as major compounds, while the second strain, isolate MN28 ${ }^{\top}$, contained $14: 03-\mathrm{OH}, 16: 0$ and $18: 1 \mathrm{cis} 11$ as the predominant fatty acids. On the basis of almost-complete 16S rRNA gene sequences, both strains could be allocated to the Nevskia branch of the class Gammaproteobacteria. The sequence similarities for strains MN154.3 ${ }^{\top}$ and $\mathrm{MN} 28^{\top}$ with respect to the most closely related type strains of this branch were 90.5 and $94.1 \%$, respectively. The sequence similarity between strains $M N 154.3^{\top}$ and $M N 28^{\top}$ was $90.6 \%$. The DNA G $+C$ content of strain MN154.3 ${ }^{\top}$ was 62.8 mol\% and that for strain $M N 28^{\top}$ was $64.9 \mathrm{~mol} \%$. Both strains possessed ubiquinone-8 as the major quinone. On the basis of the $16 \mathrm{~S}$ rRNA gene sequences of these two new isolates and several phenotypic differences exhibited with respect to known species of the Nevskia branch, strains $\mathrm{MN} 154.3^{\top}$ and $\mathrm{MN} 28^{\top}$ represent two novel genera and species, for which the names Alkanibacter difficilis gen. nov., sp. nov. and Singularimonas variicoloris gen. nov., sp. nov. are proposed. The type strain of Alkanibacter difficilis gen. nov., sp. nov. is MN154.3 ${ }^{\top}$ (=DSM $14804^{\top}=\mathrm{LMG} 22842^{\top}$ ) and that of Singularimonas variicoloris gen. nov., sp. nov. is MN28 $8^{\top}\left(=\mathrm{DSM} 15731^{\top}=\mathrm{LMG} 22844^{\top}\right)$.
During characterization of the hexane-degrading microbial community in a hexane-treated, full-scale biofilter for waste gas treatment, several groups of bacteria were isolated. Because hexane is a hydrophobic compound with low water solubility but high cytotoxic potential, microorganisms that can utilize it are of great interest. Two strains, designated MN154.3 $3^{\mathrm{T}}$ and $\mathrm{MN} 28^{\mathrm{T}}$, showed good growth on hexane and on several other short-chain alkanes. Analysis of almost-complete 16S rRNA gene sequences from strains $\mathrm{MN} 154.3^{\mathrm{T}}$ and $\mathrm{MN} 28^{\mathrm{T}}$ resulted in the placement of these strains in the Nevskia branch of the class Gammaproteobacteria. Sequence differences of more than $5 \%$ between these strains and type strains known to belong to this branch prompted us to characterize strains $\mathrm{MN} 154.3^{\mathrm{T}}$ and MN28 ${ }^{\mathrm{T}}$ in more detail.

†Present address: Fachhochschule Flensburg, Institut für Verfahrenstechnik und Biotechnologie, Kanzleistraße 91-93, 24943 Flensburg, Germany.

The GenBank/EMBL/DDBJ accession numbers for the 16S rRNA gene sequences of strain MN154.3 ${ }^{\top}$ and strain $\mathrm{MN}^{\mathrm{T}} 8^{\top}$ are $\mathrm{AJ} 313020$ and AJ555478, respectively.
The strains were enriched from $1 \mathrm{~g}$ filter material and then cultivated in defined medium consisting of $0.8 \mathrm{~g} \mathrm{~K}_{2} \mathrm{HPO}_{4}$, $0.2 \mathrm{~g} \mathrm{KH}_{2} \mathrm{PO}_{4}, 0.5 \mathrm{~g} \mathrm{MgSO}_{4} .7 \mathrm{H}_{2} \mathrm{O}, 0.01 \mathrm{~g} \mathrm{FeSO}_{4} .7 \mathrm{H}_{2} \mathrm{O}$, $1.0 \mathrm{~g}\left(\mathrm{NH}_{4}\right)_{2} \mathrm{SO}_{4}, 1 \mathrm{ml}$ trace element solution and $5 \mathrm{ml}$ vitamin solution. The medium solution was then made up to 11 with double-distilled water. Strain $\mathrm{MN} 154.3^{\mathrm{T}}$ was cultivated in medium adjusted to $\mathrm{pH} 5.0$ and strain $\mathrm{MN} 28^{\mathrm{T}}$ was grown in medium adjusted to $\mathrm{pH} 7.0$. The trace element solution contained the following $\left(\mathrm{l}^{-1}\right): 3.0 \mathrm{~g}$ $\mathrm{Na}_{2}$-EDTA, $0.05 \mathrm{~g} \mathrm{MnCl}_{2} \cdot 2 \mathrm{H}_{2} \mathrm{O}, 0.19 \mathrm{~g} \mathrm{CoCl}_{2} \cdot 6 \mathrm{H}_{2} \mathrm{O}$, $0.041 \mathrm{~g} \mathrm{ZnCl}_{2}, 0.006 \mathrm{~g} \mathrm{H}_{3} \mathrm{BO}_{3}, 0.024 \mathrm{~g} \mathrm{NiCl}_{2} .6 \mathrm{H}_{2} \mathrm{O}$, $0.002 \mathrm{~g} \mathrm{CuCl}_{2}$ and $0.018 \mathrm{~g} \mathrm{NaMoO}_{4} \cdot 2 \mathrm{H}_{2} \mathrm{O}$. The $\mathrm{pH}$ was adjusted to 6.0 . The vitamin solution contained the following $\left(1^{-1}\right)$ : $0.01 \mathrm{~g}$ thiamine, $0.02 \mathrm{~g}$ nicotinic acid, $0.02 \mathrm{~g}$ pyridoxine hydrochloride, $0.01 \mathrm{~g} p$-aminobenzoic acid, $0.02 \mathrm{~g}$ riboflavin, $0.02 \mathrm{~g}$ pantothenic acid, $0.001 \mathrm{~g}$ biotin and $0.001 \mathrm{~g}$ cyanocobalamin and was adjusted to a $\mathrm{pH}$ of 7.0. Liquid cultures $50 \mathrm{ml}$ in volume were grown in screw-capped $100 \mathrm{ml}$ flasks supplemented with $10 \mu \mathrm{l}$ hexane. For solid media, $15 \mathrm{~g}$ agar $\mathrm{l}^{-1}$ was included in the defined medium. Agar plates were incubated in 51 desiccators, $1 \mathrm{ml}$ hexane was placed in a separate beaker in the desiccator to supply hexane to the desiccator 
atmosphere. All incubations were performed at $30{ }^{\circ} \mathrm{C}$. Both strains grew well on agar plates with hexane as the sole carbon source. In liquid minimal medium, strain MN $28^{\mathrm{T}}$ showed weak growth or no growth at all. Growth with other carbon sources was tested in $20 \mathrm{ml}$ tubes with $5 \mathrm{ml}$ liquid medium. Amino acids, carbohydrates and carbonic acids were tested at a concentration equivalent to $60 \mathrm{mM}$ carbon. Alkanes were used at a concentration of $0.2 \%(\mathrm{v} /$ v). Growth experiments with alkanes were performed in screw-capped tubes. In liquid minimal medium, strain MN154. $3^{\mathrm{T}}$ showed good growth on $\beta$-hydroxybutyric acid, weak growth on succinate and no growth on L-arabinose, D-fructose, D-alanine, D-threonine, D-glucose, L-aspartic acid, L-lysine or citrate. Strain MN154. ${ }^{\mathrm{T}}$ grew well with pentane, hexane and decane, but not with heptane or octane. Growth on nonane was weak with this strain. The optimal growth temperature for strain $\mathrm{MN} 154.3^{\mathrm{T}}$ was $30{ }^{\circ} \mathrm{C}$; growth was slightly slower at $23{ }^{\circ} \mathrm{C}$ and considerably slower at $37{ }^{\circ} \mathrm{C}$. No growth was observed at 13 or $45{ }^{\circ} \mathrm{C}$. Strain $\mathrm{MN} 28^{\mathrm{T}}$ did not grow with any of these alkanes or with $\beta$-hydroxybutyric acid in liquid minimal medium. An expanded collection of carbon sources was tested for strains MN154. $3^{\mathrm{T}}$ and MN28 ${ }^{\mathrm{T}}$ using the API 20NE system and API $50 \quad \mathrm{CH}$ strips with API $50 \mathrm{CHB} / \mathrm{E}$ medium (bioMérieux) and using Biolog GN microplates. All tests were performed according to the manufacturers' instructions, but the incubation time was extended to 10 days. Strain MN154.3 ${ }^{\mathrm{T}}$ did not show growth or positive reactions in any of these test systems. However, strain $\mathrm{MN} 28^{\mathrm{T}}$ gave positive results for gelatinase activity in the API 20NE system and also for acid production from glycerol and sucrose and hydrolysis of aesculin (with the API $50 \mathrm{CH}$ system). In the Biolog GN system, strain $\mathrm{MN} 28^{\mathrm{T}}$ was positive for the oxidation of Tween 40, D-glucose, methyl pyruvate, monomethyl succinate, cis-aconitic acid, $\beta$ hydroxybutyric acid, $\alpha$-ketobutyric acid, succinic acid, bromosuccinic acid, succinamic acid, alaninamide, L-alanyl glycine, L-glutamic acid, glycyl L-glutamic acid, L-threonine and urocanic acid.

For fatty acid analyses, the isolates and two reference strains were grown, according to their specific requirements, in different media. Strain $\mathrm{MN} 28^{\mathrm{T}}$ was grown on trypticase soy agar plates (Becton Dickinson) for 7 days; strain MN154.3 $3^{\mathrm{T}}$ failed to grow on trypticase soy agar and so was grown on defined medium with hydroxybutyrate at $30{ }^{\circ} \mathrm{C}$ for 9 days. The reference strains Nevskia ramosa DSM $11499^{\mathrm{T}}$ and Hydrocarboniphaga effusa DSM $16095^{\mathrm{T}}$ were obtained from the Deutsche Sammlung von Mikroorganismen und Zellkulturen (Braunschweig, Germany). For the fatty acid analyses, N. ramosa DSM $11499^{\mathrm{T}}$ was grown for 7 days at $25^{\circ} \mathrm{C}$ on DSM medium 828 as recommended by the culture collection. $H$. effusa DSM $16095^{\mathrm{T}}$ was grown on trypticase soy agar for 6 days at $30{ }^{\circ} \mathrm{C}$. Saponification, methylation and extraction of the fatty acids from isolates and reference strains were performed as described by Sasser (1990). The fatty acid methyl ester extracts were analysed using a GC with a flame ionization detector (GC-FID; model 6890, Hewlett Packard) equipped with a $5 \%$ phenyl-methyl-silicone capillary column. The identities of the fatty acids were verified by GC-MS with a gas chromatograph (model 5890, series II; Hewlett Packard) equipped with a $5 \%$ phenylmethyl-silicone capillary column and a model 5972 mass selective detector. The chromatographic conditions used were as described previously (Lipski \& Altendorf, 1997). The positions of double bonds and of cyclopropane, hydroxy and methyl groups were determined from the carboxyl group of the fatty acid molecule, according to the recommendations of the IUPAC-IUB Commission on Biochemical Nomenclature (1977). Both isolates had a straight-chain fatty acid pattern dominated by vaccenic acid and palmitic acid (18:1cis11 and 16:0). Isolate MN154. $3^{\mathrm{T}}$ could be differentiated from isolate $\mathrm{MN} 28^{\mathrm{T}}$ by the presence of the cyclopropane fatty acids 17:0 cyclo910 and 19:0 cyclo11-12 in the former organism. Conversely, isolate $\mathrm{MN} 28^{\mathrm{T}}$ was characterized by the presence of the branched-chain fatty acids $12: 0$ iso, 14:0 iso and 16:0 iso and the monounsaturated fatty acid 16: 1cis11 (Table 1). Both strains showed 14:0 $3-\mathrm{OH}$ as the

Table 1. Fatty acid compositions (\%) of strain $\mathrm{MN} 154.3^{\top}$, strain $\mathrm{MN}^{2} 8^{\top}$ and two reference strains

Strains: $1, \mathrm{MN} 154.3^{\mathrm{T}} ; 2, \mathrm{MN} 28^{\mathrm{T}} ; 3$, N. ramosa DSM $11499^{\mathrm{T}} ; 4, H$. effusa DSM $16095^{\mathrm{T}}$.

\begin{tabular}{|c|c|c|c|c|}
\hline Fatty acid & 1 & 2 & $3^{*}$ & 4 \\
\hline $12: 0$ iso & & 2.2 & & \\
\hline $12: 0$ & 4.3 & 11.4 & 3.2 & 16.3 \\
\hline $12: 02-\mathrm{OH}$ & & 1.5 & & \\
\hline $12: 03-\mathrm{OH}$ & & 0.7 & & 3.4 \\
\hline $14: 0$ iso & & 0.4 & & \\
\hline $14: 0$ & 1.2 & 2.5 & 20.5 & 2.2 \\
\hline $14: 1$ trans 2 & & 1.1 & & \\
\hline $15: 0$ & & 0.5 & & 0.8 \\
\hline ECL $15.082 \dagger$ & & 0.9 & & \\
\hline $14: 02-\mathrm{OH}$ & 2.1 & & & \\
\hline $14: 03-\mathrm{OH}$ & 6.6 & 11.5 & & 2.8 \\
\hline $16: 0$ iso & & 4.6 & & \\
\hline $16: 1 c i s 9$ & 3.8 & 2.2 & 16.1 & 16.4 \\
\hline $16: 1 c i s 11$ & & 3.0 & & \\
\hline $16: 0$ & 30.1 & 15.6 & 42.2 & 18.9 \\
\hline $17: 0$ cyclo9-10 & 2.4 & & & \\
\hline $17: 1$ cis 11 & & 0.5 & & \\
\hline $16: 02-\mathrm{OH}$ & & 0.8 & & 1.6 \\
\hline $16: 03-\mathrm{OH}$ & 1.3 & 0.3 & & \\
\hline $18: 1 c i s 9$ & 2.3 & & & \\
\hline $18: 1$ cis 11 & 15.8 & 37.3 & 17.9 & 37.6 \\
\hline $18: 0$ & 14.9 & 0.4 & & \\
\hline 19:0 cyclo11-12 & 15.3 & 2.1 & & \\
\hline
\end{tabular}

${ }^{*}$ N. ramosa DSM $11499^{\mathrm{T}}$ contained four more lipids (equivalent chain lengths: 13.528, ECL 15.355, ECL 15.553 and ECL 17.379) whose mass spectra indicated long-chain monounsaturated alcohols.

$\dagger$ ECL, Equivalent chain length. 
predominant hydroxy fatty acid. The presence of a straightchain fatty acid pattern was in accord with the profiles of the two reference strains but was different from the patterns of most other genera of the family Xanthomonadaceae, the fatty acid profiles of which are dominated by iso/anteiso fatty acids (Finkmann et al., 2000; Kim et al., 2006; Lee et al., 2005; An et al., 2005). To date, the only species of the family Xanthomonadaceae known to possess a straight-chain fatty acid pattern is Xylella fastidiosa. This species comprises a group of nutritionally fastidious and plant-pathogenic strains, which were isolated exclusively from the xylem of plant tissue (Wells et al., 1987). The specific fatty acids, the ecology and the $16 \mathrm{~S}$ rRNA gene sequence of $X$. fastidiosa serve to differentiate this species clearly from the two novel isolates and two reference strains analysed in this study. The allocation of the genera Nevskia and Hydrocarboniphaga to the family Xanthomonadaceae is currently based exclusively on 16S rRNA gene sequence data (Palleroni et al., 2004; Saddler \& Bradbury, 2005) but both the deep branching position within this family and the chemotaxonomic differences suggest separation of the Nevskia branch from the family Xanthomonadaceae and the definition of a separate family for this particular group of species.

Isoprenoid quinones and polar lipids were extracted and analysed using the small-scale integrated procedure of Minnikin et al. (1984). Quinones were separated into menaquinones and ubiquinones by using TLC. Separation of the ubiquinones according to the different isoprenyl chain lengths was performed on HPTLC-RP $18 \mathrm{~F}_{254}$ plates (Merck) according to Kroppenstedt (1982). The two novel isolates and the two reference strains all possessed a quinone of the ubiquinone- 8 type. The polar lipid patterns of the two novel isolates were different from each other and also from the patterns of the two reference strains (Fig. 1).

For 16S rRNA gene sequencing, bacterial DNA was extracted from pure cultures by using the DNeasy Tissue kit (Qiagen). Almost-complete 16S rRNA gene sequence PCR products were obtained as described previously (Friedrich et al., 2002). Full-length sequences of the PCR products were obtained by GAG BioScience (Bremen, Germany). Sequences were checked manually using the CHROMAS programme (Technelysium) and assembled using the DNAMAN programme (Lynnon BioSoft). The sequences were compared with sequences in the National Centre for Biotechnology Information nucleotide sequence database, using the BLAST program (Altschul et al., 1997). The BLAST analyses of the 16S rRNA gene sequence for strain MN154. $3^{\mathrm{T}}$ revealed $N$. ramosa Soe $1^{\mathrm{T}}$ as the type strain with the most similar sequence (94.1\% similarity). For strain $\mathrm{MN} 28^{\mathrm{T}}$, the next most closely related type strain was H. effusa $\mathrm{AP} 103^{\mathrm{T}}(90.5 \%$ sequence similarity). The sequence similarity between strains $\mathrm{MN} 154.3^{\mathrm{T}}$ and MN28 ${ }^{\mathrm{T}}$ was $90.6 \%$. A phylogenetic analysis with the MEGA program, version 3.1 (Kumar et al., 2004), showed that both the reference species and isolates MN154. $3^{\mathrm{T}}$ and $\mathrm{MN} 28^{\mathrm{T}}$ are members of a deep branch within the family

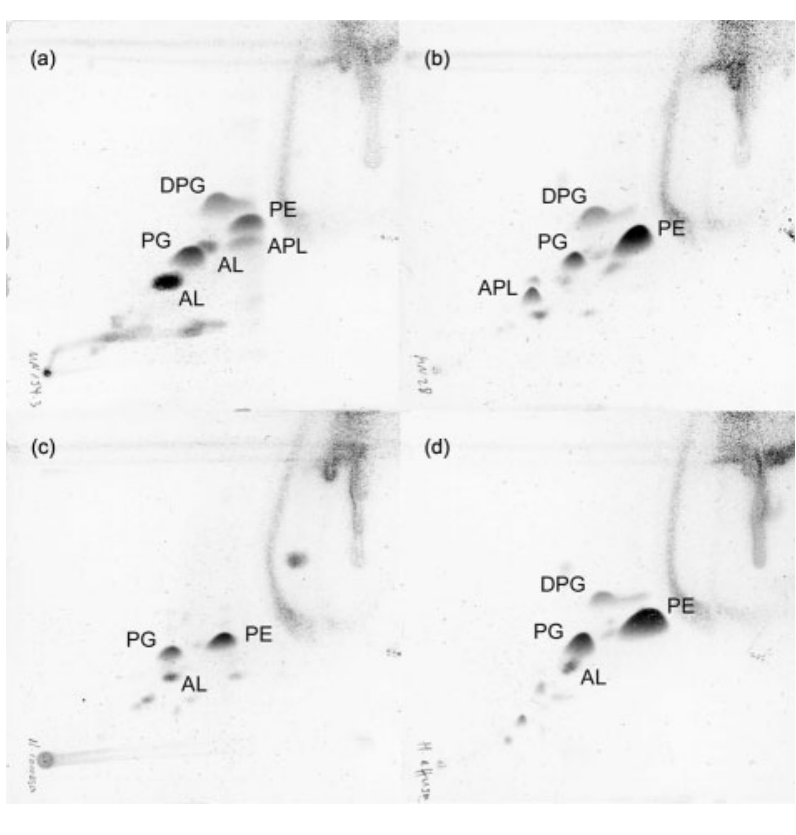

Fig. 1. Polar lipid patterns of strain $M N 154.3^{\top}$ (a), strain $M N 28^{\top}$ (b), N. ramosa DSM $11499^{\top}$ (c) and $H$. effusa DSM $16095^{\top}$ (d). $\mathrm{AL}$, unknown aminolipid; $\mathrm{APL}$, unknown aminophospholipid; DPG, diphosphatidylglycerol; PE, phosphatidylethanolamine; PG, phosphatidylglycerol.

Xanthomonadaceae (Fig. 2). Remarkably, one species from this branch, $H$. effusa, is able to grow on aliphatic hydrocarbons from C6 to C19 (Palleroni et al., 2004). At least one strain of this species, $H$. effusa LX1, was isolated from a toluene-treated biofilter (Juteau et al., 1999).

The $\mathrm{G}+\mathrm{C}$ content of the novel isolates was determined after degradation of isolated genomic DNA by P1 nuclease and alkaline phosphatase, followed by separation and quantification of the resulting nucleosides by using HPLC (Mesbah et al., 1989). Lambda-DNA was used as the reference. The DNA G + C content of strain MN154.3 ${ }^{\mathrm{T}}$ was $62.8 \mathrm{~mol} \%(\mathrm{SD}, 0.19)$ and that for strain $\mathrm{MN} 28^{\mathrm{T}}$ was $64.9 \mathrm{~mol} \%$ (SD, 0.07).

The $5 \%$ differences in gene sequence similarity between the novel isolates and their most closely related type strains and between the novel isolates themselves, as well as the presence of several phenotypic differences (Table 2), led us to the proposal of two novel genera and species to accommodate strains $\mathrm{MN} 154.3^{\mathrm{T}}$ and $\mathrm{MN} 28^{\mathrm{T}}$. Phenotypically, strain MN154. $3^{\mathrm{T}}$ can be differentiated from the most closely related species, N. ramosa, on the basis of the DNA G + C content, which is $67.8 \%$ for $N$. ramosa Soe ${ }^{\mathrm{T}}$ but only $62.8 \%$ for MN154. $3^{\mathrm{T}}$. Rosette-like microcolonies at the surfaces of liquid cultures, typical of $N$. ramosa, were never observed for strain MN154. $3^{\mathrm{T}}$. In contrast to $N$. ramosa Soe $^{\mathrm{T}}$, strain MN154.3 ${ }^{\mathrm{T}}$ exhibited the cyclopropane fatty acids 17:0 cyclo9-10 and 19:0 cyclo11-12. Both strains showed different polar lipid profiles. Both species from this 


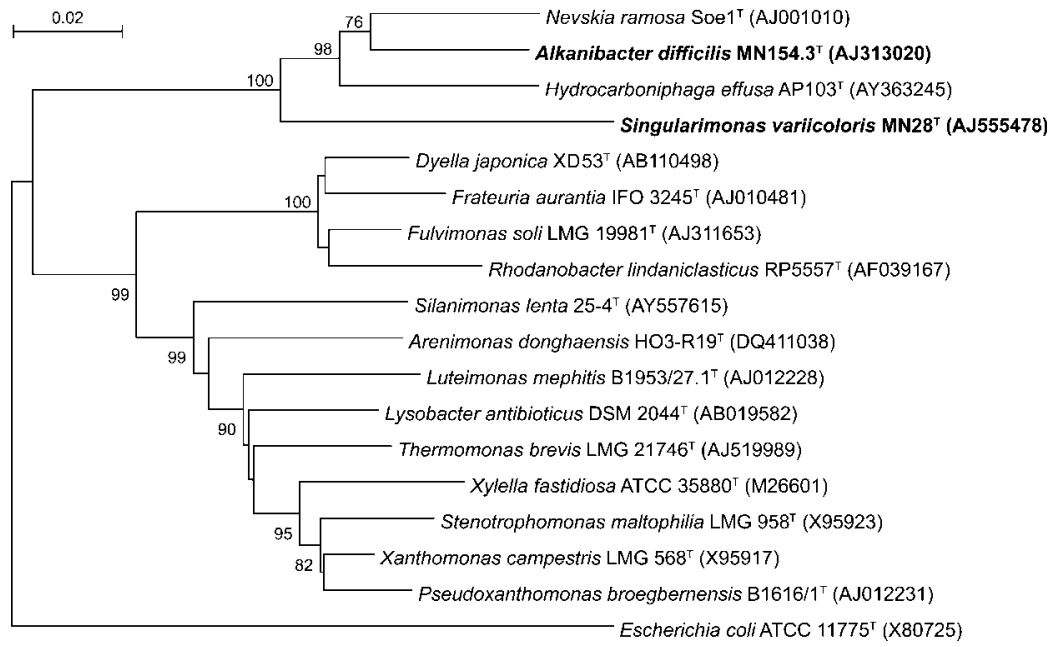

Fig. 2. Neighbour-joining phylogenetic tree, based on 16S rRNA gene sequences, showing the positions of the isolates within the family Xanthomonadaceae. Bootstrap percentages (based on 1000 replications) $>70 \%$ are shown at nodes. Escherichia coli was used as the outgroup. Bar, 0.02 substitutions per nucleotide position.

branch, $N$. ramosa and $H$. effusa, can grow on pyruvate and lactate, unlike our novel isolates.

During the revision of this manuscript, the species Solimonas soli was described (Kim et al., 2007). The type strain of this species, Solimonas soli DCY12 ${ }^{\mathrm{T}}$, shows a $16 \mathrm{~S}$ rRNA gene sequence similarity of $98.2 \%$ with respect to strain MN $28^{\mathrm{T}}$, which suggests a strong phylogenetic relationship between these taxa. However, for Solimonas soli $\mathrm{DCY}_{12}{ }^{\mathrm{T}}$, a DNA $\mathrm{G}+\mathrm{C}$ content of $40.5 \mathrm{~mol} \%$ was described; this is considerably lower than the value $(64.9 \mathrm{~mol} \%)$ found for strain $\mathrm{MN} 28^{\mathrm{T}}$. In contrast to the high level of sequence similarity, the difference in the DNA G+C contents $(>20 \mathrm{~mol} \%)$ supports the differentiation of these two taxa at the genus level. The taxonomic relationship of these two

Table 2. Phenotypic characteristics of strains $M N 154.3^{\top}$, $\mathrm{MN} 28^{\top}$ and related taxa

Strains: $1, \mathrm{MN} 154.3^{\mathrm{T}} ; 2, \mathrm{MN} 28^{\mathrm{T}} ; 3, \mathrm{~N}$. ramosa DSM $11499^{\mathrm{T}} ; 4, \mathrm{H}$. effusa DSM $16095^{\mathrm{T}}$; data for 3 and 4 are from Stürmeyer et al. (1998), Palleroni et al. (2004) or this study. +, Positive; -, negative; ND, no data available.

\begin{tabular}{|lcccc|}
\hline Characteristic & $\mathbf{1}$ & $\mathbf{2}$ & $\mathbf{3}$ & $\mathbf{4}$ \\
\hline DNA G+C content (mol\%) & 62.8 & 64.9 & 67.8 & 60 \\
Presence of iso-branched fatty acids & - & + & - & - \\
Presence of cyclopropane fatty acids & + & - & - & - \\
$\quad(>10 \%)$ & & & & \\
Swarming on agar surface & - & - & $\mathrm{ND}$ & + \\
Growth on complex media & - & + & $\mathrm{ND}$ & + \\
Rosette-like colonies at air-water & - & - & + & - \\
interface & & & & \\
Growth on: & & & & \\
$\quad$ Lactate and pyruvate & - & - & + & + \\
Malate & - & - & - & + \\
Succinate & - & + & - & + \\
Glutamate & - & + & + & + \\
Acetate & - & - & + & - \\
\end{tabular}

taxa should be clarified by means of a direct experimental comparison between the two strains.

\section{Description of Alkanibacter gen. nov.}

Alkanibacter (Al.ka.ni.bac'ter. N.L. n. alkanum saturated hydrocarbon; N.L. masc. n. bacter from Gr. n. bakterion rod; N.L. masc. n. Alkanibacter rod assimilating alkanes).

Cells are aerobic, non-spore-forming rods. Gram-negative and oxidase- and catalase-positive. The major fatty acids are $16: 0$ and $18: 1$ cis 11 . The quinone type is ubiquinone- 8 . The type species is Alkanibacter difficilis.

\section{Description of Alkanibacter difficilis sp. nov.}

Alkanibacter difficilis (diff'i.cil.is. L. masc. adj. difficilis difficult, because it is difficult to cultivate).

Displays the following characteristics in addition to those given in the genus description. Cells are small rods of $0.6 \pm 0.1 \times 0.9 \pm 0.3 \mu \mathrm{m}$. Colonies are transparent, yellow, circular and $1 \mathrm{~mm}$ in diameter on defined-medium agar with added hexane. $\mathrm{KOH}$ and aminopeptidase tests give positive results and Gram-staining is negative. Grows on hydroxybutyric acid and succinate (weakly) as carbon sources. Optimal growth is at $30{ }^{\circ} \mathrm{C}$; no growth occurs at 13 or $45{ }^{\circ} \mathrm{C}$. The type strain, MN154.3 $3^{\mathrm{T}}$, grows on pentane, hexane and decane. No growth occurs in nutrient broth or on trypticase soy agar. The major fatty acids are 16:0, $18: 0,18: 1$ cis 11 and $19: 0$ cyclo11-12; $14: 03-\mathrm{OH}$ is present. The DNA G $+\mathrm{C}$ content is $62.8 \mathrm{~mol} \%$.

The type strain, MN154.3 $3^{\mathrm{T}}\left(=\mathrm{DSM} 14804^{\mathrm{T}}=\mathrm{LMG} 22842^{\mathrm{T}}\right.$ ), was isolated from an industrial biofilter.

\section{Description of Singularimonas gen. nov.}

Singularimonas (Sin.gu.la.ri.mo'nas. L. adj. singularis extraordinary; Gr. fem n. monas unit, cell; N.L. fem. n. Singularimonas extraordinary unit). 
Cells are aerobic, non-spore-forming rods. Gram-negative and oxidase- and catalase-positive. The major fatty acids are 16:0 and 18:1cis 11 ; iso-branched fatty acids are also present. The quinone type is ubiquinone- 8 . The type species is Singularimonas variicoloris.

\section{Description of Singularimonas variicoloris sp. nov.}

Singularimonas variicoloris (va.ri.i.co.lo'ris. L. adj. varius varying; L. gen. n. coloris of colour; N.L. gen n. variicoloris of varying colour).

Displays the following characteristics in addition to those given in the genus description. Catalase-positive (weak reaction). Colonies vary in colour between yellow, orange and brown. Colonies on trypticase soy agar are $1-3 \mathrm{~mm}$ in diameter, umbonate and are each surrounded by a flat, pale white rim. The colour is more intense in the centre of the colony. Gram-staining is negative and the $\mathrm{KOH}$ and aminopeptidase tests give positive results. The DNA G $+\mathrm{C}$ content is $64.9 \mathrm{~mol} \%$ (SD, 0.07). Growth is positive with hexane on minimal medium agar but is negative in liquid medium. Positive for growth on the following: Tween 40, $\alpha$-D-glucose, methyl pyruvate, monomethyl succinate, cisaconitic acid, $\beta$-hydroxybutyric acid, $\alpha$-ketobutyric acid, succinic acid, bromosuccinic acid, succinamic acid, alaninamide, L-alanylglycine, L-glutamic acid, glycyl Lglutamic acid, L-threonine and urocanic acid. The gelatinase reaction is positive. No growth occurs on the following: $\alpha$-cyclodextrin, dextrin, glycogen, Tween $80, \mathrm{~N}$ acetyl-D-galactosamine, $\mathrm{N}$-acetyl-D-glucosamine, adonitol, L-arabinose, D-arabitol, cellobiose, i-erythritol, D-fructose, L-fucose, D-galactose, gentiobiose, glucose, myo-inositol, $\alpha$ D-lactose, lactulose, maltose, D-mannitol, D-mannose, melibiose, methyl $\beta$-D-glucoside, D-psicose, raffinose, Lrhamnose, D-sorbitol, sucrose, trehalose, turanose, xylitol, acetic acid, citric acid, formic acid, D-galactonic acid lactone, D-galacturonic acid, D-gluconic acid, D-glucosaminic acid, D-glucuronic acid, $\alpha$-hydroxybutyric acid, $\gamma$ hydroxybutyric acid, $p$-hydroxyphenylacetic acid, itaconic acid, $\alpha$-ketoglutaric acid, $\alpha$-ketovaleric acid, DL-lactic acid, malonic acid, propionic acid, quinic acid, D-saccharic acid, sebacic acid, caprate, adipate, malate, glucuronamide, Dalanine, L-alanine, L-asparagine, L-aspartic acid, glycyl Laspartic acid, L-histidine, hydroxy-L-proline, L-leucine, Lornithine, L-phenylalanine, L-proline, L-pyroglutamic acid, D-serine, L-serine, DL-carnitine, $\gamma$-aminobutyric acid, inosine, uridine, thymidine, phenylethylamine, putrescine, 2aminoethanol, 2,3-butanediol, glycerol, DL- $\alpha$-glycerol phosphate, glucose 1-phosphate and glucose 6-phosphate. Negative for reduction of nitrate, indole production, arginine dihydrolase, urease, $\beta$-galactosidase and $\beta$-glucosidase. The major fatty acids are 14:03-OH, 16:0 and 18:1 cis 11 ; iso-branched fatty acids are present. The DNA $\mathrm{G}+\mathrm{C}$ content is $64.9 \mathrm{~mol} \%$ (SD, 0.07).

The type strain, MN28 ${ }^{\mathrm{T}}\left(=\mathrm{DSM} 15731^{\mathrm{T}}=\mathrm{LMG} 22844^{\mathrm{T}}\right)$, was isolated from an industrial biofilter.

\section{Acknowledgements}

We are grateful to Professor Hans G. Trüper for his help and valuable suggestions regarding the etymology.

\section{References}

Altschul, S. F., Madden, T. L., Schaffer, A. A., Zhang, J., Zhang, Z., Miller, W. \& Lipman, D. J. (1997). Gapped BLAST and PSI-BLAST: a new generation of protein database search programs. Nucleic Acids Res 25, 3389-3402.

An, D. S., Im, W. T., Yang, H. C., Yang, D. C. \& Lee, S. T. (2005). Dyella koreensis sp. nov., a $\beta$-glucosidase-producing bacterium. Int J Syst Evol Microbiol 55, 1625-1628.

Finkmann, W., Altendorf, K., Stackebrandt, E. \& Lipski, A. (2000). Characterization of $\mathrm{N}_{2} \mathrm{O}$-producing Xanthomonas-like isolates from biofilters as Stenotrophomonas nitritireducens sp. nov., Luteimonas mephitis gen. nov., sp. nov. and Pseudoxanthomonas broegbernensis gen. nov., sp. nov. Int J Syst Evol Microbiol 50, 273-282.

Friedrich, U., Prior, K., Altendorf, K. \& Lipski, A. (2002). High bacterial diversity of a waste gas-degrading community in an industrial biofilter as shown by a $16 \mathrm{~S}$ rDNA clone library. Environ Microbiol 4, 721-734.

IUPAC-IUB Commission on Biochemical Nomenclature (1977). The nomenclature of lipids: recommendations, 1976. Eur J Biochem 79, 11-21.

Juteau, P., Larocque, R., Rho, D. \& LeDuy, A. (1999). Analysis of the relative abundance of different types of bacteria capable of toluene degradation in a compost biofilter. Appl Microbiol Biotechnol 52, 863-868.

Kim, M. K., Im, W. T., In, J. G., Kim, S. H. \& Yang, D. C. (2006). Thermomonas koreensis sp. nov., a mesophilic bacterium isolated from a ginseng field. Int J Syst Evol Microbiol 56, 1615-1619.

Kim, M. K., Kim, Y.-J., Cho, D.-H., Yi, T.-H., Soung, N.-K. \& Yang, D.-C. (2007). Solimonas soli gen. nov., sp. nov., isolated from soil of a ginseng field. Int J Syst Evol Microbiol 57, 2591-2594.

Kroppenstedt, R. M. (1982). Anwendung chromatographischer HPVerfahren (HPTLC und HPLC) in der Bakterien-Taxonomie. GIT Lab Med 5, 266-276 (in German).

Kumar, S., Tamura, K. \& Nei, M. (2004). MEGA3: integrated software for molecular evolutionary genetics analysis and sequence alignment. Brief Bioinform 5, 150-163.

Lee, E. M., Jeon, C. O., Choi, I., Chang, K. S. \& Kim, C. J. (2005). Silanimonas lenta gen. nov., sp. nov., a slightly thermophilic and alkaliphilic gammaproteobacterium isolated from a hot spring. Int $J$ Syst Evol Microbiol 55, 385-389.

Lipski, A. \& Altendorf, K. (1997). Identification of heterotrophic bacteria isolated from ammonia-supplied experimental biofilters. Syst Appl Microbiol 20, 448-457.

Mesbah, M., Premachandran, U. \& Whitman, W. B. (1989). Precise measurement of the $\mathrm{G}+\mathrm{C}$ content of deoxyribonucleic acid by high-performance liquid chromatography. Int J Syst Bacteriol 39, 159-167.

Minnikin, D. E., O’Donnell, A. G., Goodfellow, M., Alderson, G., Athalye, M., Schaal, A. \& Parlett, J. H. (1984). An integrated procedure for the extraction of bacterial isoprenoid quinones and polar lipids. J Microbiol Methods 2, 233-241.

Palleroni, N. J., Port, A. M., Chang, H. K. \& Zylstra, G. J. (2004). Hydrocarboniphaga effusa gen. nov., sp. nov., a novel member of the $\gamma$-Proteobacteria active in alkane and aromatic hydrocarbon degradation. Int J Syst Evol Microbiol 54, 1203-1207. 
Saddler, G. S. \& Bradbury, J. F. (2005). Family I. Xanthomonadaceae fam. nov. In Bergey's Manual of Systematic Bacteriology, 2nd edn, vol. 2 (The Proteobacteria), part B (The Gammaproteobacteria), p. 63. Edited by D. J. Brenner, N. R. Krieg, J. T. Staley \& G. M. Garrity. New York: Springer.

Sasser, M. (1990). Identification of bacteria through fatty acid analysis. In Methods in Phytobacteriology, pp. 199-204. Edited by Z. Klement, K. Rudolph \& D. C. Sands. Budapest: Akademiai Kiado.
Stürmeyer, H., Overmann, J., Babenzien, H.-D. \& Cypionka, H. (1998). Ecophysiological and phenotypic studies of Nevskia ramosa in pure culture. Appl Environ Microbiol 64, 1890-1894.

Wells, J. M., Raju, B. C., Hung, H.-Y., Weisburg, W. G., MandelcoPaul, L. \& Brenner, D. J. (1987). Xylella fastidiosa gen. nov., sp. nov: gram-negative, xylem-limited, fastidious plant bacteria related to Xanthomonas spp. Int J Syst Bacteriol 37, 136-143. 